\title{
Erratum to: Anemia Management in the Elderly Dialysis Patient: Is It Different?
}

\author{
Iain C. Macdougall
}

\section{Erratum to:}

Chapter 9 in: Madhukar Misra, Dialysis in Older Adults, DOI 10.1007/978-1-4939-3320-4_9

The labels were spelled incorrectly in Figure 9.2. The below revised image has been replaced with the corrected labels:

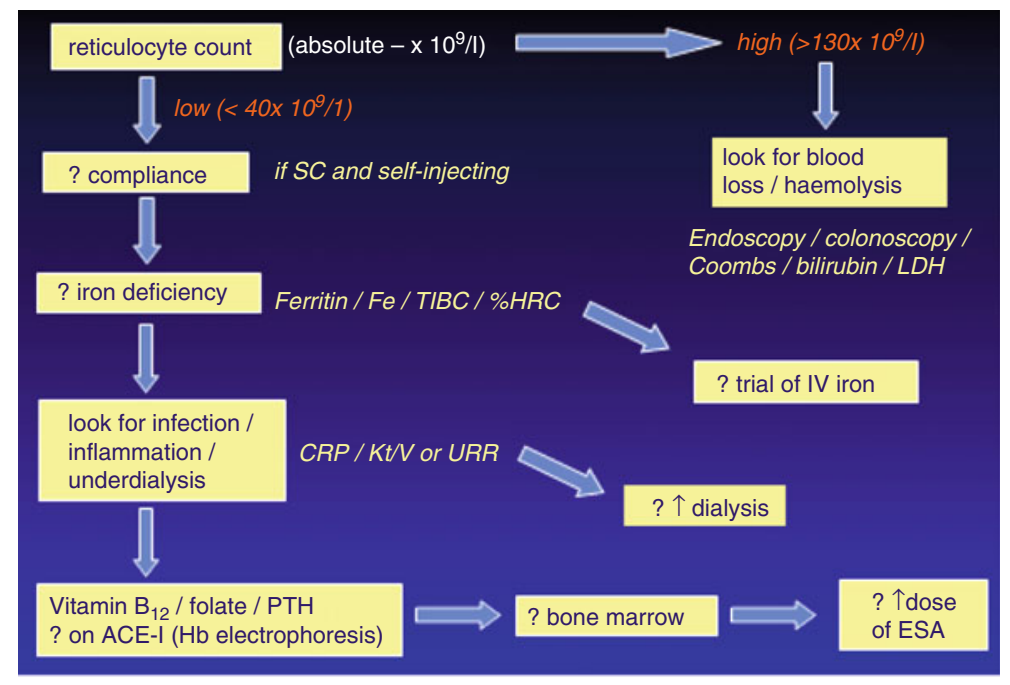

The online version of the original chapter can be found under DOI:10.1007/978-1-4939-3320-4_9

I.C. Macdougall, BSc, MD, FRCP

Department of Renal Medicine, King's College Hospital, London, UK

Renal Unit, King's College Hospital, London SE5 9RS, UK

e-mail: iain.macdougall@nhs.net 